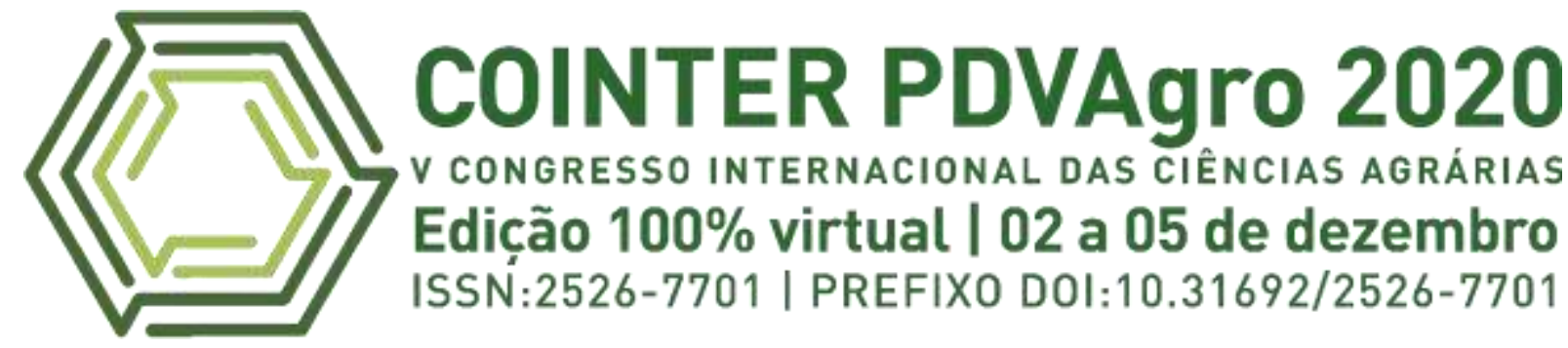

\title{
ELABORAÇÃO DE SORVETE VEGANO ADICIONADO DE AÇAI
}

\author{
PREPARACIÓN DE HELADO VEGANO AÑADIDO DE AÇAI
}

\section{PREPARATION OF VEGAN ICE CREAM ADDED FROM AÇAI}

\author{
Apresentação: Comunicação Oral \\ Rosinete de Souza Passos ${ }^{1}$; Sumaya Ferrerira Guedes²; Claudinéia Aparecida Queli Geraldi³ ${ }^{3}$ Giorgo \\ Ferreira Guedes ${ }^{4}$; Raquel Aparecida Loss ${ }^{5}$
}

DOI: https://doi.org/10.31692/2526-7701.VCOINTERPDVAgro.0415

\begin{abstract}
RESUMO
O sorvete, é considerado um alimento saboroso fabricado a partir de uma emulsão estabilizada, tendo como principal matéria prima produtos lácteos. Assim, indivíduos com intolerância ou alergia e a determinado componente deste ou pessoas veganas não podem consumi-lo. Um excelente substituto ao leite, é o extrato de coco, conhecido como leite de coco, que possui características nutricionais semelhantes ao leite. Pensando nessa necessidade, este trabalho teve por objetivo o desenvolvimento de um sorvete vegano saborizado de açaí, substituindo os ingredientes de origem animal por produtos de origem vegetal, destinando aos veganos ou as pessoas com restrições alimentares relacionados a presença do leite. Foram elaboradas três formulações e submetidas às avaliações físicoquímicas (umidade, $\mathrm{pH}$, resíduo mineral fixo e acidez titulável) e sensoriais (teste de preferência, aceitação, escala do ideal e intenção de compra). Na análise físico-química, a substituição do leite de coco em pó pelo leite de arroz e pela mistura de ambos os leites não interferiu na umidade e nas cinzas. Para a acidez, essa substituição resultou em uma pequena redução na acidez. A análise sensorial mostrou que os provadores gostaram igualmente de todas as formulações e classificaram todas elas como ideal para os atributos avaliados. O índice de aceitabilidade foi de $97,38, \%$ para o sorvete elaborado com $100 \%$ com leite de coco, $96,31 \%$ para a formulação em que o leite de coco em pó foi substituído pelo leite de arroz em pó e $97,41 \%$ para a mistura de ambos os leites. Assim, a elaboração de sorvete vegano a base de leite de coco e com substituições parciais deste pelo leite de arroz apresenta potencial como um novo produto.
\end{abstract}

Palavras-Chave: Alergia alimentar, leite de arroz, leite de coco.

\section{RESUMEN}

El helado se considera un alimento sabroso elaborado a partir de una emulsión estabilizada, con los productos lácteos como principal materia prima. Así, las personas con intolerancia o alergia y cierto componente de esta o las personas veganas no pueden consumirlo. Pensando en esta necesidad, este

\footnotetext{
${ }^{1}$ Engenharia de Alimentos, Universidade do Estado de Mato Grosso, rosinete-passos@ hotmail.com

2 Agronomia, Universidade do Estado de Mato Grosso, sumayaguedes@unemat.br

${ }^{3}$ Agronomia, Universidade do Estado de Mato Grosso, claudigeraldi@onda.com.br

${ }^{4}$ Zootecnista, Prefeitura de Rondonópolis, giorgozoo@ hotmail.com

${ }^{5}$ Doutorado, Universidade do Estado de Mato Grosso, raquelloss@unemat.br
} 
trabajo tuvo como objetivo desarrollar un helado vegano aromatizado con açaí, sustituyendo ingredientes de origen animal por productos de origen vegetal, destinados a veganos o personas con restricciones dietéticas relacionadas con la presencia de leche. Se prepararon tres formulaciones y se sometieron a evaluaciones físico-químicas (humedad, $\mathrm{pH}$, residuo mineral fijo y acidez titulable) y sensoriales (comparación pareada, prueba de aceptación, escala de ideal y intención de compra ). En el análisis físico-químico, la sustitución de leche de coco en polvo por leche de arroz y la mezcla de ambas leches no interfirió con la humedad y las cenizas. Para la acidez, esta sustitución resultó en una pequeña reducción de la acidez. El análisis sensorial mostró que a los catadores les gustaron por igual todas las formulaciones y las clasificaron como ideales para los atributos evaluados. El índice de aceptabilidad fue del 97,38\% para los helados elaborados con leche de coco 100\%, del 96,31\% para la formulación en la que la leche de coco en polvo se reemplazó por leche de arroz en polvo y del 97,41\% para la mezcla de ambas leches. Así, la producción de helado vegano a base de leche de coco y su sustitución parcial por leche de arroz tiene potencial como nuevo producto.

Palabras Clave: Alergia alimentaria, leche de arroz, leche de coco.

\begin{abstract}
Ice cream is considered a tasty food manufactured from a stabilized emulsion, with dairy products as the main raw material. Thus, individuals with intolerance or allergy and a certain component of this or vegan people cannot consume it. This work aimed at the development of a flavored vegan ice cream of açaí, substituting the ingredients of animal origin for products of vegetable origin. Three formulations were prepared and submitted to physical chemical evaluations and sensorial evaluations. In the physical chemical analysis, the replacement of coconut milk powder by rice milk and the mixture of both milks did not interfere in moisture and ash. For acidity, this substitution resulted in a small reduction in acidity. Sensory analysis showed that tasters also liked all formulations and rated all of them as ideal for assessed attributes. The acceptability index was $97.38 \%$ for ice cream made with $100 \%$ coconut milk, $96.31 \%$ for the formulation in which the powdered coconut milk was replaced with powdered rice milk and $97.41 \% \%$ for the mixture of both milks. Thus, the preparation of vegan ice cream based on coconut milk and with partial substitutions of this by rice milk presents potential as a new product.
\end{abstract}

Keywords: Food allergy, rice milk, coconut milk.

\title{
INTRODUÇÃO
}

Os sorvetes, conforme a portaria n 379, de abril de 1999 têm como definição serem gelados comestíveis: são produtos alimentícios obtidos a partir de uma emulsão de gorduras e proteínas, com ou sem a adição de outros ingredientes e substâncias, ou de uma mistura de água, açúcares e outros ingredientes e substâncias que tenham sido submetidas ao congelamento, em condições que garantam a conservação do produto no estado congelado ou parcialmente congelado, durante o armazenamento, o transporte, a comercialização e a entrega ao consumo (BRASIL, 1999).

Por sua matéria-prima principal ser o leite de vaca, pessoas com estilo de alimentação vegana e que possuem alergia a determinado componente do mesmo, como a sua proteína, ou intolerância a lactose, não podem consumi-lo. Indivíduos que tem intolerância a lactose possuem distúrbios em seu sistema digestivo, de maneira que não conseguem fazer digestão da lactose presente no sorvete a base de leite (PERREIRA et al., 2012). 
Desta forma, o leite de coco pode ser uma opção para substituir o leite de vaca, uma vez que não possui a lactose, substância responsável pelo desconforto a pessoas que possuem intolerância ou são alérgicas. O leite de coco é uma emulsão aquosa constituída de gorduras, proteínas, açúcares, sais minerais e água. Esse alimento é rico em triptofano, um aminoácido que é responsável pela produção de serotonina no cérebro, sendo que esta é um hormônio que atua na regulação do sono e na sensação de bem-estar no organismo humano (IAROS e PINHEIRO, 2016). Desta forma, o leite de coco pode ser uma opção para substituir o leite de vaca, uma vez que não possui a lactose, substância responsável pelo desconforto a pessoas que possuem intolerância ou são alérgicas. Segundo Dias.et al. (2018), o leite de coco é uma alternativa que proporciona várias opções de preparações, e torna-se um alimento que interessa as indústrias alimentícias atualmente, em especial pela elaboração de novos produtos funcionais. Além disso, o leite de coco encontra potencial como ingrediente na elaboração de alimentos destinados ao público que sofre com restrições alimentares em relação aos componentes do leite ou ainda com estilo de alimentação vegana.

O açaí é considerado alimento de alto valor calórico, com elevado percentual de lipídeos, e nutricional, pois é rico em proteínas, minerais (potássio e cálcio) e vitaminas, em especial a vitamina E. Além disso, o açaí possui propriedades antioxidantes, que atuam na eliminação dos radicais livres (MARTINS e JÚNIOR, 2014).

Desta forma, o presente trabalho teve como objetivo a elaboração de um sorvete, vegano a base de leite de coco e saborizado com açaí, avaliando as suas características físico-químicas e sensoriais.

\section{FUNDAMENTAÇÃO TEÓRICA}

\section{Sorvetes}

Segundo a Resolução RDC n²67 de 2003 da Agência Nacional de Vigilância Sanitária (ANVISA), gelados comestíveis são definidos como:

"Produtos alimentícios obtidos a partir de uma emulsão de gorduras e proteínas, como ou sem a adição de outros ingredientes e substâncias, ou de uma mistura de água, açúcares e outros ingredientes bem como substâncias que garantam a conservação do produto no estado congelado ou parcialmente congelado, durante o armazenamento, o transporte, a comercialização e a entrega ao consumo" (BRASIL,2003).

O sorvete é elaborado a partir de uma emulsão estabilizada, sendo composta por água, 
gordura, açúcar, estabilizante, emulsificante, corante e aromatizante. Desta forma, pode-se dizer que o sorvete é uma espuma que contém bolhas de ar, sendo estas cobertas por cristais de gelo, glóbulos de gorduras e cristais de lactose. As bolhas têm a função de tornar o sorvete mais leve e macio, além de atuarem como isolantes do frio intenso (GUEDES et al., 2018).

Em relação aos principais ingredientes do sorvete, o açúcar é responsável pelo sabor doce e pode contribuir na cremosidade e influenciar no ponto de congelamento. Já a cor, aroma e sabor do sorvete são influenciados pelos aromatizantes adicionados na formulação do sorvete. Os aromatizantes podem ser naturais ou artificiais, sendo que os naturais mais usados são encontrados nas frutas cítricas, já os sintéticos são compostos pelas substâncias químicas e aromáticas e pelos aromas idênticos ao natural (SHEIN,2016).

A gordura é responsável pelas características de corpo e de derretimento, e confere textura ao sorvete, contribuindo para a formação de cristais de gelo menores, permitindo a estabilidade e reduzindo a quantidade de estabilizante (BOFF et al., 2013). A porcentagem de gordura presente nos sorvetes pode variar de acordo com a sua composição básica, porém, para os sorvetes comerciais o teor de gordura se encontra entre 10 a $12 \%$ da composição total do sorvete (SOLER e VEIGA,2001).

Os estabilizantes o possuem alta capacidade de retenção de água e são utilizados para evitar a cristalização e a recristalização de gelo que podem ser formados durante a estocagem. Esses compostos também são utilizados na elaboração de sorvetes para evitar a separação do soro de leite durante o congelamento e descongelamento (SOLER e VEIGA,2001).

Os emulsificantes são compostos químicos que possuem uma parte hidrofóbica e outra hidrofílica em suas moléculas e tem a função de diminuir a tensão superficial entre o ar e a gordura, melhorando assim a estabilidade das bolhas de ar, além de promover a uniformidade durante o batimento (TIMM,1989; SOUZA et al.,2010).

\section{Leite de vegetais}

O termo "leites" de vegetais se dá à bebida própria para consumo, obtida de matériaprima de origem vegetal, sendo que está apresenta características organolépticas e físicoquímicas semelhantes ao leite de origem animal (DIAS et al.,2018).

O interesse em relação aos leites vegetais vem aumentando cada vez mais, uma vez que estes apresentam elevado valor nutritivo e são uma alternativa para pessoas com alergia ou intolerância ao leite animal. O alimento é obtido a partir de grão, polpas e sementes diversas, tais como a castanha do brasil, linhaça, coco, arroz, aveia dentre outros (DIAS et al., 2018). 
Os leites de vegetais são ideais para quem não consome alimentos de origem animal, como as pessoas adeptas ao estilo de alimentação natural e para quem é alérgico a proteína do leite. Com são alimentos de origem vegetal não contém lactose e são fontes de potássio, vitaminas do complexo $\mathrm{B}$, gorduras de boa qualidade e boa quantidade de fibras (BASILIO,2017)

\section{Leite de coco}

O Brasil possui cerca de 280 mil hectares cultivados com coqueiro, distribuídos, praticamente, em quase todo o território nacional com produção próxima dos dois bilhões de frutos (MARTINS e JESUS JÚNIOR, 2014).

O país é o quarto maior produtor mundial com uma produção aproximada de 2,8 milhões de toneladas, em uma área colhida de 287 mil hectares de coqueiros. Esta condição de destaque do Brasil no cenário mundial de produção de coco se sobressai ainda mais quando se compara aos países da América do Sul, região na qual a produção brasileira é responsável por mais de 80\% (EMBRAPA, 2011).

Os produtos provenientes do fruto (verde e maduro) são os mais utilizados e comercializados, sendo o óleo principal componente, além de ácido láurico, leite de coco, fibra, farinha e água de coco (EMBRAPA, 2011).

O leite de coco é uma emulsão aquosa extraída do endosperma do fruto por processo mecânico adequado, é formado de gorduras, proteínas, açúcares, sais minerais e água, sendo os lipídeos e a água os ingredientes principais, também é rico em triptofano. Este aminoácido é responsável pela produção de serotonina no cérebro, desde que quantidades suficientes de niacina, piridoxina e zinco estejam presentes. A serotonina é um hormônio que regula o sono e a sensação de bem-estar no organismo humano. O leite de coco é uma alternativa que proporciona várias opções de preparações, e torna-se um alimento que interessa as indústrias alimentícias atualmente, em especial pela elaboração de novos produtos funcionais (DIAS et al., 2018)

\section{Leite de arroz.}

O Brasil é o maior produtor de arroz do hemisfério Sul, tendo este cereal uma grande importância na alimentação da população, na qual tem-se predominantemente o consumo deste cereal em sua forma branca, classificado como longo-fino (PEREIRA e MORAES, 2014).

O arroz (Oryza sativa) é um vegetal pertencente à família das gramíneas, mais recentemente denominada de família das poáceas, sendo classificado como uma das principais 
fontes de energia para diversas populações humanas. Esse cereal também é um alimento muito nutritivo, composto por amido (a maior parte); proteínas; sais minerais (fósforo, ferro e cálcio); vitaminas do complexo B. Contém também baixo teor de lipídeos e oito aminoácidos essenciais presentes no endosperma e no farelo do grão que favorecem a digestibilidade (PEREIRA E MORAES, 2014).

O extrato de arroz representa uma das alternativas para substituir o leite de vaca pelas suas propriedades nutricionais e baixo custo, pois contém menores índices de proteínas e cálcio, e possui uma grande quantidade de carboidratos. O leite de arroz no mercado é melhorado com cálcio e vitaminas. O leite em pó de arroz pode ser utilizado em várias preparações de molhos, cremes e sobremesa (SOARES JUNIOR et al., 2010)

Açaí

O açaizeiro (Euterpe oleracea Mart.) é nativo da Amazônia brasileira e o Estado do Pará é o principal centro de dispersão natural dessa palmácea. Populações espontâneas também são encontradas nos Estados do Amapá, Maranhão, Mato Grosso, Tocantins; e em países da América do Sul (Venezuela, Colômbia, Equador, Suriname e Guiana) e da América Central (Panamá). Dos frutos do açaizeiro é extraído o vinho, polpa ou simplesmente açaí, como é conhecido na região. O açaí é habitualmente consumido com farinha de mandioca, associado ao peixe, camarão ou carne, sendo o alimento básico para as populações de origem ribeirinha. Com o açaí são fabricados sorvetes, licores, doces, néctares e geleias, podendo ser aproveitado, também, para a extração de corantes e antocianina (MARTINS e JESUS JÚNIOR, 2014).

O açaí é considerado alimento de alto valor calórico, com elevado percentual de lipídeos, e nutricional, pois é rico em proteínas e minerais. O açaí possui um alto teor de antocianinas, possuem função de antioxidante, assegura melhor circulação sanguínea e protegem o organismo contra o acúmulo de placas de depósitos de lipídeos, causadores da arteriosclerose. O açaí é rico em minerais, principalmente potássio e cálcio e, dentre as vitaminas, destaca-se a vitamina $\mathrm{E}$, um antioxidante natural que atua na eliminação dos radicais livres (MARTINS e JÚNIOR, 2014).

O consumo dessa polpa, rica em lipídeos essenciais e de boa qualidade nutricional, contribui para garantir o crescimento e bom funcionamento do corpo humano em geral, uma vez que esses nutrientes participam de várias reações metabólicas importantes no organismo. Entretanto a polpa não pode ser considerada como uma fonte de ferro, sugere-se uma complementação desse mineral na dieta com alimentos fonte de ferro de maior 
PRINCIPAL, et al.

biodisponibilidade (MENEZES et al., 2008).

\section{METODOLOGIA}

\section{Elaboração do leite de coco}

Para a elaboração do sorvete vegano foi utilizado o leite de coco em substituição ao leite de vaca. O leite de coco usado na elaboração dos sorvetes foi obtido conforme descrito por Carvalho (2007). Os frutos foram descascados (retirada do mesocarpo) utilizando uma faca de inox higienizada. Para facilitar a retirada do endocarpo, os frutos foram submetidos a um choque térmico em autoclave a $120^{\circ} \mathrm{C}$ por 20 minutos.

A polpa descascada, foi lavada em água corrente, imersa em banho de metabissulfito de sódio a $0,2 \%$, sofrendo em seguida a trituração em um multiprocessador. $\mathrm{O}$ material foi aquecido a uma temperatura de $50^{\circ} \mathrm{C}$ por 15 minutos, com adição de $10 \%$ de água para facilitar a extração. Após esse período o líquido foi submetido a pasteurização por 10 minutos (a contar do início da fervura). O leite assim obtido foi armazenado sob refrigeração $\left(4{ }^{\circ} \mathrm{C}\right)$ por no máximo 48 horas, até a sua utilização como matéria-prima na elaboração de sorvete.

Após a obtenção do leite de coco, parte deste foi usado para a elaboração do condensado de coco. Para tanto, foi adicionado açúcar tipos cristal na proporção de 1:1 (leite: açúcar) e a mistura foi submetida a cocção, sob constante agitação, por aproximadamente 40 minutos, obtendo assim o condensado de coco.

\section{Preparo do sorvete vegano}

Os ingredientes creme de soja, leite de arroz em pó, leite de coco em pó, liga neutra, emulsificante e a polpa de açaí utilizados para o preparo do sorvete foram adquiridos no comércio local dos municípios de Cuiabá e Barra do Bugres - MT.

Para o preparo do sorvete, foram seguidas as instruções de fabricação artesanal contidas nas embalagens de emulsificante e liga neutra da marca Selecta®. O processo consistiu em misturar, o condensado de coco (preparado previamente), o creme de soja, o leite de coco, os leites em pó (coco ou arroz), a polpa de açaí e a liga neutra em liquidificador doméstico por três minutos ou até se obter uma mistura homogênea. A massa homogênea foi armazenada a $0^{\circ} \mathrm{C}$ 
por 4 horas. A massa congelada foi dividida em pedaços e submetida a mistura em batedeira doméstica juntamente com o emulsificante por aproximadamente cinco minutos para a incorporação de ar. O sorvete foi transferido para recipiente próprio para sorvete, coberto com filme plástico, para que não haver formação de cristais de gelo, e armazenada a $0^{\circ} \mathrm{C}$ até o momento das análises físico-químicas e sensoriais.

Foram elaboradas três diferentes formulações de sorvete, que diferenciaram entre si pela composição dos ingredientes (leite em pó de coco, arroz ou mistura de ambos), conforme mostra a Tabela 1. As quantidades apresentadas nessa tabela correspondem a necessária para obtenção de 1 litro de sorvete. Para cada uma das formulações, foram preparadas três réplicas dos sorvetes para maior confiabilidade dos resultados.

Tabela 1: Formulação do sorvete vegano a base de leite de coco e saborizado com açaí

\begin{tabular}{cccc}
\hline Ingredientes & $\begin{array}{c}\text { Formulação 1 } \\
\text { (leite de coco) }\end{array}$ & $\begin{array}{c}\text { Formulação 2 } \\
\text { (leite de arroz) }\end{array}$ & $\begin{array}{c}\text { Formulação 3 } \\
\text { (leite de coco e de arroz) }\end{array}$ \\
\hline Leite de coco líquido & $250 \mathrm{~mL}$ & $250 \mathrm{~mL}$ & $250 \mathrm{~mL}$ \\
\hline Creme de soja & $100 \mathrm{~g}$ & $100 \mathrm{~g}$ & $100 \mathrm{~g}$ \\
\hline Condensado de coco & $165 \mathrm{~g}$ & $165 \mathrm{~g}$ & $165 \mathrm{~g}$ \\
\hline Açúcar de coco & $30 \mathrm{~g}$ & $30 \mathrm{~g}$ & $30 \mathrm{~g}$ \\
\hline Liga neutra & $10 \mathrm{~g}$ & $10 \mathrm{~g}$ & $10 \mathrm{~g}$ \\
\hline Emulsificante & $20 \mathrm{~g}$ & $20 \mathrm{~g}$ & $20 \mathrm{~g}$ \\
\hline Leite em pó & $10 \mathrm{~g}$ & $10 \mathrm{~g}$ & $5 \mathrm{~g} \mathrm{de} \mathrm{cada}$ \\
\hline Polpa de açaí & $150 \mathrm{~g}$ & $150 \mathrm{~g}$ & $150 \mathrm{~g}$ \\
\hline
\end{tabular}

Fonte: Própria (2020).

\section{Análises físico-químicas}

As análises físico-químicas que foram realizadas no sorvete foram de umidade, $\mathrm{pH}$, resíduo mineral fixo (cinzas) e acidez titulável. Todas foram efetuadas de acordo com o Instituto Adolfo Lutz (2008). Todas as análises foram realizadas em triplicatas.

Para a umidade, foram pesados aproximadamente $5 \mathrm{~g}$ de amostra em placas de petri, aquecidas em estufa a $105{ }^{\circ} \mathrm{C}$ durante 24 horas, resfriadas em dessecador até atingir a temperatura ambiente e, em seguida, pesadas (IAL,2008).

A determinação de $\mathrm{pH}$ foi realizada diretamente nas amostras, sem a necessidade de diluição, pois as mesmas se encontrava em estado líquido. A determinação foi realizada em pHmetro previamente calibrado, operando o aparelho de acordo com as instruções do fabricante (IAL, 2008).

Para determinar o conteúdo de resíduo mineral fixo, foram pesados aproximadamente 
$5 \mathrm{~g}$ de amostra em cadinhos previamente tarados, aquecidos em mufla a $550^{\circ} \mathrm{C}$, até que as cinzas apresentassem uma coloração branca ou levemente acinzentadas. Posteriormente a amostra foi resfriada em dessecador até a temperatura ambiente e pesada.

Para a acidez titulável, foram pesados aproximadamente $5 \mathrm{~g}$ de amostra em um erlenmeyer com $30 \mathrm{~mL}$ de água destilada, adicionando três gotas de solução indicadora fenolftaleína e em seguida foi titulado com solução de hidróxido de sódio $0,1 \mathrm{~mol} / \mathrm{L}$ previamente padronizada (fc: 0,9987) até se obter a coloração ligeiramente rósea (IAL,2008). Os resultados foram expressos em termos de \% de ácido cítrico presente nas amostras.

\section{Análise sensorial}

As formulações do sorvete foram avaliadas sensorialmente pelos testes de comparação pareada, aceitação, escala do ideal e teste de intenção de compra. Os testes foram realizados em cabines individuais, com iluminação branca e participação de 74 julgadores voluntários não treinados, de ambos os sexos e com idades entre 18 e 38 anos. As amostras de sorvete foram oferecidas aos provadores em copos descartáveis de 50mL, codificados com números aleatórios de três dígitos, juntamente com água mineral sem gás.

Também foi avaliado o índice de aceitabilidade (IA) dos produtos elaborados, por meio da expressão IA $(\%)=$ A x 100/B, sendo que A representa a nota média obtida para o produto e B a nota máxima dada ao produto (SOUZA et al., 2018).

\section{Teste de Comparação Pareada - Preferência}

No teste de preferência por comparação pareada, as amostras foram avaliadas pelo provador pela comparação entre as três amostras de sorvete (100\% leite de coco em pó, 100\% leite de arroz em pó e 50\% leite de coco, 50\% leite de arroz) em relação a sua preferência. As amostras foram apresentadas simultaneamente aos provadores, sendo que os mesmos indicaram a amostra preferida. Os atributos referentes a preferência da amostra analisada foram complementados com análise estatística descritiva, de acordo com o teste de comparação preferência bicaudal (IAL, 2008).

\section{Teste de aceitação}

No teste de aceitação, as amostras foram avaliadas em relação ao atributo global, aroma, sabor, textura e cor, de acordo com metodologia adaptada da proposta do Instituto Adolfo Lutz (2008). Os provadores utilizaram escala hedônica, estruturada, de 9 pontos, ancoradas nos 
extremos pelos termos "gostei muitíssimo" e " desgostei muitíssimo". Os dados coletados foram avaliados estatisticamente pela análise de variância, ANOVA e teste de Tukey.

\section{Teste da escala do ideal}

No teste de aceitação por escala do ideal, os provadores expressaram o quão próximo do ideal os atributos acidez, doçura, textura e gosto herbáceo (feijão cru) encontrava-se em cada uma das amostras fornecidas. As amostras foram analisadas pela seguinte escala: elevada, ideal ou baixa (IAL, 2008). Os resultados obtidos foram calculados em forma de porcentagem de julgamentos.

\section{Teste intenção de compra}

No teste de intenção de compra, os provadores expressaram a intenção ou não de compra do produto que lhes foi oferecido. As amostras foram avaliadas pela escala com cinco termos pré-definidos, variando de certamente compraria; talvez compraria/ talvez não compraria e certamente não compraria (IAL, 2008). Os resultados obtidos foram calculados em porcentagem de julgamentos.

\section{Análise estatística}

A análise estatística do teste sensorial de preferência foi realizada usando o software Assistat, (versão 7.7, 2014) pela aplicação do teste de Tukey, utilizando o nível de probabilidade de 5\% para avaliar a diferença significativa entre as médias.

\section{RESULTADOS E DISCUSSÃO}

\section{Análises físico-químicas}

As diferentes formulações de sorvete vegano a base de leite de coco e saborizado com polpa de açaí foram submetidas a análise físico-química em relação ao conteúdo de umidade, cinzas, $\mathrm{pH}$, acidez e proteínas. As formulações 1 a 3 diferem entre si na composição em relação ao leite em pó utilizado, sendo $100 \%$ de leite de coco (1), $100 \%$ de leite de arroz (2) e $50 \%$ de cada um (3).

A umidade está relacionada com a quantidade de água contida nos alimentos, com essencial importância econômica, pois pode interferir no teor de sólidos de um alimento assim 
como em sua perecibilidade, agindo na estabilidade química, deterioração microbiológica e alterações sensoriais nos alimentos (GOMES; OLIVEIRA, 2011). A Tabela 2 apresenta o teor de umidade obtido nas diferentes formulações.

Tabela 2: Umidade para os sorvetes veganos saborizados com açaí

\begin{tabular}{cc}
\hline Formulações & Umidade \% \\
\hline Formulação 1 & $74,23 \pm 0,51$ \\
Formulação 2 & $73,94 \pm 0,57$ \\
Formulação 3 & $74,35 \pm 0,45$ \\
\hline
\end{tabular}

Fonte: Própria (2020).

Com relação a umidade, é possível observar que a substituição do leite de coco em pó pelo leite de arroz ou pela mistura do leite de coco e arroz não contribuiu para alterações pronunciadas na umidade do sorvete (Formulações 1 a 3 ). Neste trabalho pode-se observar que o teor de umidade variou de $74,94 \pm 0,57 \%$ a $74,35 \pm 0,45 \%$ sendo que esses valores são superiores aos encontrado por Boff et al. (2013) quando elaborou um sorvete de leite bovino sabor chocolate com fibra de laranja como substituto de gordura e obteve 63,03\% de umidade. Rechsteiner (2009) também obteve uma umidade menor que a do presente trabalho em sorvete de baunilha elaborado com leite de vaca, com uma umidade de 66,72\%. Já Porfírio (2017) encontrou uma umidade de $85,60 \%$ para sorvete vegano elaborado a base de extrato hidrossolúvel de soja.

A quantidade de cinzas presente no alimento é relacionada ao resíduo inorgânico que permanece após a queima da matéria orgânica, e que é constituída principalmente de sódio, potássio, cálcio e magnésio, mas também aparece em pequenas quantidades de alumínio, ferro, manganês e zinco (CECCHI, 2003). A Tabela 3 apresenta o teor de cinzas nas diferentes formulações de sorvete vegano a base de leite de coco e saborizado com açaí.

Tabela 3: Teor de cinzas para os sorvetes veganos saborizados com açaí

\begin{tabular}{cc}
\hline Tratamentos & Cinzas (\%) \\
\hline Formulação 1 & $0,42 \pm 0,020$ \\
Formulação 2 & $0,40 \pm 0,011$ \\
Formulação 3 & $0,38 \pm 0,011$ \\
\hline
\end{tabular}

Fonte: Própria (2020).

O sorvete elaborado com $100 \%$ leite de coco foi o que apresentou maior teor de cinzas. 
Silva Júnior e Lannes (2011) encontrou 1,11\% de cinzas na formulação a base de leite bovino utilizando óleo de palma. Pereira (2014) encontrou 1,38\% para sorvete de morango diet elaborado com soro de leite bovino. Os dados de cinzas deste trabalho dever ter sido baixo pelo fato das formulações não possuírem nenhum teor de leite bovino, visto que a maior parte dos minerais em sorvetes é resultante do leite bovino (PEREIRA,2014).

A acidez de um alimento está relacionada com várias características do produto final, encontrando-se em análise de deterioração e de estabilidade do alimento (CECCHI, 2003). Nos alimentos, o pH é um importante aliado para o controle de qualidade, pois podem diferenciar como alimentos ácidos $(\mathrm{pH}<7,00)$, neutros $(\mathrm{pH}=7,00)$ e básicos $(\mathrm{pH}>7,00)$ por meio da concentração de íons de hidrogênio livres (IAL,2008). A análise de pH pode auxiliar na avaliação do grau de decomposição do alimento, com base no nível de alcalinidade produzida pelas reações e processos químicos e bioquímicos que o mesmo sofre, alterando o nível de $\mathrm{pH}$ que constituem determinados padrões (GOMES; OLIVEIRA, 2011). A Tabela 4 apresenta o teor de acidez em ácido cítrico e pH nas diferentes formulações de sorvete vegano a base de leite de coco e saborizado com açaí.

Tabela 4: Acidez em ácido cítrico e pH para os sorvetes veganos saborizados com açaí

\begin{tabular}{ccc}
\hline Tratamentos & Acidez (\%) & pH \\
\hline Formulação 1 & $0,15 \pm 0,020$ & $5,34 \pm 0,066$ \\
Formulação 2 & $0,12 \pm 0,023$ & $5,35 \pm 0,288$ \\
Formulação 3 & $0,14 \pm 0,024$ & $6,38 \pm 0,108$ \\
\hline
\end{tabular}

Fonte: Própria (2020).

Pela Tabela 4 é possível observar que o sorvete vegano elaborado a base de leite de coco e saborizado com polpa de açaí apresentou baixa acidez e pH pouco ácido. O valor da acidez total titulável do sorvete vegano obtido neste estudo foi superior ao encontrado por Rodrigues e Moretti (2008) de 0,08\% em uma bebida de extrato de soja e polpa de pêssego e Uliana (2009) encontrou 0,09\% em uma bebida mista de extrato de soja com suco de amora, porém foi inferior ao encontrado por Ribeiro (2015) na elaboração de bebida mista de extrato hidrossolúvel de soja com adição de polpa de cupuaçu, que foi de $0,83 \%$. Campideli et al. (2015) encontrou o valor de 5,55 para sorvete de mirtilo adicionado de chia e leite bovino em sua composição. Já Pereira (2010) encontrou valores maiores que as formulações deste estudo, de 6,86 na produção de sorvete com utilização de extrato hidrossolúvel de soja. Isso pode ter ocorrido devido ao fato de que o mesmo apenas substituiu parcialmente o leite em pó desnatado pelo extrato de soja. Silva Júnior e Lannes (2011) encontrou 6,51 como pH para sorvete de chocolate formulado 
com óleo de palma a base de leite bovino. Corradini et al. (2014) encontrou valores de pH de 6,46 a 6,62 para sorvetes elaborados com óleo de palma a base de leite de vaca.

\section{Análise sensorial}

Um alimento, além do valor nutritivo, deve ser agradável e atrair a atenção do consumidor, como resultado da harmonia dos diversos parâmetros de qualidade sensorial. A aplicação da análise sensorial tem como princípio detectar diferenças nos produtos analisados com a intenção de identificar diferenças na intensidade de determinados atributos (ARAÚJO et al., 2012).

Desta forma, os sorvetes veganos a base de leite de coco e adicionado ou não de leite de arroz em pó foram submetidos a análises sensorial. Os testes sensoriais foram aplicados em 74 provadores voluntários e não treinados com idade acima de 18 anos, para analisar a preferência, teste de aceitação, escala do ideal e teste de intenção de compra dos produtos elaborados.

O teste pareado de preferência foi complementado com análise estatística descritiva. Nesse teste não foi possível definir qual a amostra preferida, visto que pela análise estatística, considerando 74 julgadores, era necessário que no mínimo 47 assinalassem a mesma amostra como preferida e apenas 33 marcaram a formulação 3 como preferida. Do total de julgadores, 22 mostraram preferência pela formulação 1 e 19 preferiram o sorvete cuja composição era leite de coco líquido e $100 \%$ leite de arroz em pó (formulação 2).

Para o teste de aceitação foi utilizada uma escala hedônica com nove pontos, onde os julgadores avaliaram o grau de gostar ou desgostar para cada um dos atributos questionados. A escala utilizada foi: (9) gostei extremamente; (8) gostei muito; (7) gostei moderadamente; (6) gostei ligeiramente; (5) indiferente; (4) desgostei ligeiramente; (3) desgostei moderadamente; (2) desgostei muito; (1) desgostei extremamente. As médias de cada atributo, obtidas no teste de aceitação, encontram-se na Tabela 5.

Tabela 5: Média dos atributos dos sorvetes vegano saborizados com açaí

\begin{tabular}{llll}
\hline Atributos & Formulação 1 & Formulação 2 & Formulação 3 \\
\hline Atributo global & $7,53 \pm 1,42^{\mathrm{a}}$ & $7,59 \pm 1,29^{\mathrm{a}}$ & $7,74 \pm 1,35^{\mathrm{a}}$ \\
Aroma & $7,62 \pm 1,31^{\mathrm{a}}$ & $7,70 \pm 1,30^{\mathrm{a}}$ & $7,80 \pm 1,26^{\mathrm{a}}$ \\
Sabor & $7,27 \pm 1,75^{\mathrm{a}}$ & $7,50 \pm 1,65^{\mathrm{a}}$ & $7,72 \pm 1,64^{\mathrm{a}}$ \\
Textura & $7,26 \pm 1,61^{\mathrm{a}}$ & $7,20 \pm 1,84^{\mathrm{a}}$ & $7,46 \pm 1,61^{\mathrm{a}}$ \\
Cor & $7,42 \pm 1,77^{\mathrm{a}}$ & $7,09 \pm 1,82^{\mathrm{a}}$ & $7,27 \pm 1,82^{\mathrm{a}}$ \\
\hline
\end{tabular}


Letras iguais na mesma linha, os atributos não diferem entre si, pelo Teste de Tukey ao nível de probabilidade de $5 \%$.

Fonte: Própria (2020).

Pela Tabela 5, as diferentes formulações do sorvete não apresentam diferença estatisticamente significativa para nenhum dos atributos avaliados. Desta forma, pela análise estatística dos resultados do teste de aceitação, todas as formulações de sorvete são iguais e, isso pode justificar os resultados obtidos no teste de preferência, que não apontou nenhuma amostra como a preferida pelos julgadores. Apesar do teste de aceitação não ter apontado um sorvete preferido, estes apresentaram aceitação por parte dos julgadores, uma vez que lhes foram atribuídas notas entre gostei moderadamente e gostei muito.

Pelo teste da escala do ideal (Figura 1), em relação a acidez, os sorvetes não diferenciaram de forma acentuada entre si, uma vez que os percentuais em cada um dos atributos avaliados foi praticamente o mesmo, sendo que a maioria dos provadores consideram a acidez como ideal: $64 \%$ para o sorvete $100 \%$ leite de coco, $65 \%$ para a formulação em que o leite de coco em pó foi substituído pelo leite de arroz em pó e $66 \%$ para a mistura de ambos os leites. Para a doçura, assim como observado na acidez, a maioria dos provadores consideraram como ideal, sendo que para o sorvete elaborado com a mistura de leite de coco e leite de arroz o percentual foi mais elevado (80\%). Para as formulações com $100 \%$ leite de arroz e leite de coco este percentual reduziu para $62 \%$ e $60 \%$, respectivamente. Para a textura o sorvete elaborado com $100 \%$ leite de coco foi apontado por $68 \%$ dos provadores como ideal, seguido do sorvete elabora pela mistura de leites (65\%) e pelo sorvete com 100\% leite de arroz (62\%). Para o gosto herbáceo os provadores se dividiram entre o ideal e baixo, sendo que apenas 9\% dos provadores consideraram elevado o gosto herbáceo para o sorvete com 100\% leite de arroz, $11 \%$ para a mistura e $14 \%$ para o leite de coco. Assim como observado do teste de preferência e aceitação, o teste da escala do ideal não aponta nenhuma amostra como preferida, embora todas elas tenham sido classificadas como ideal por um maior percentual de julgadores, para todos os atributos avaliados 


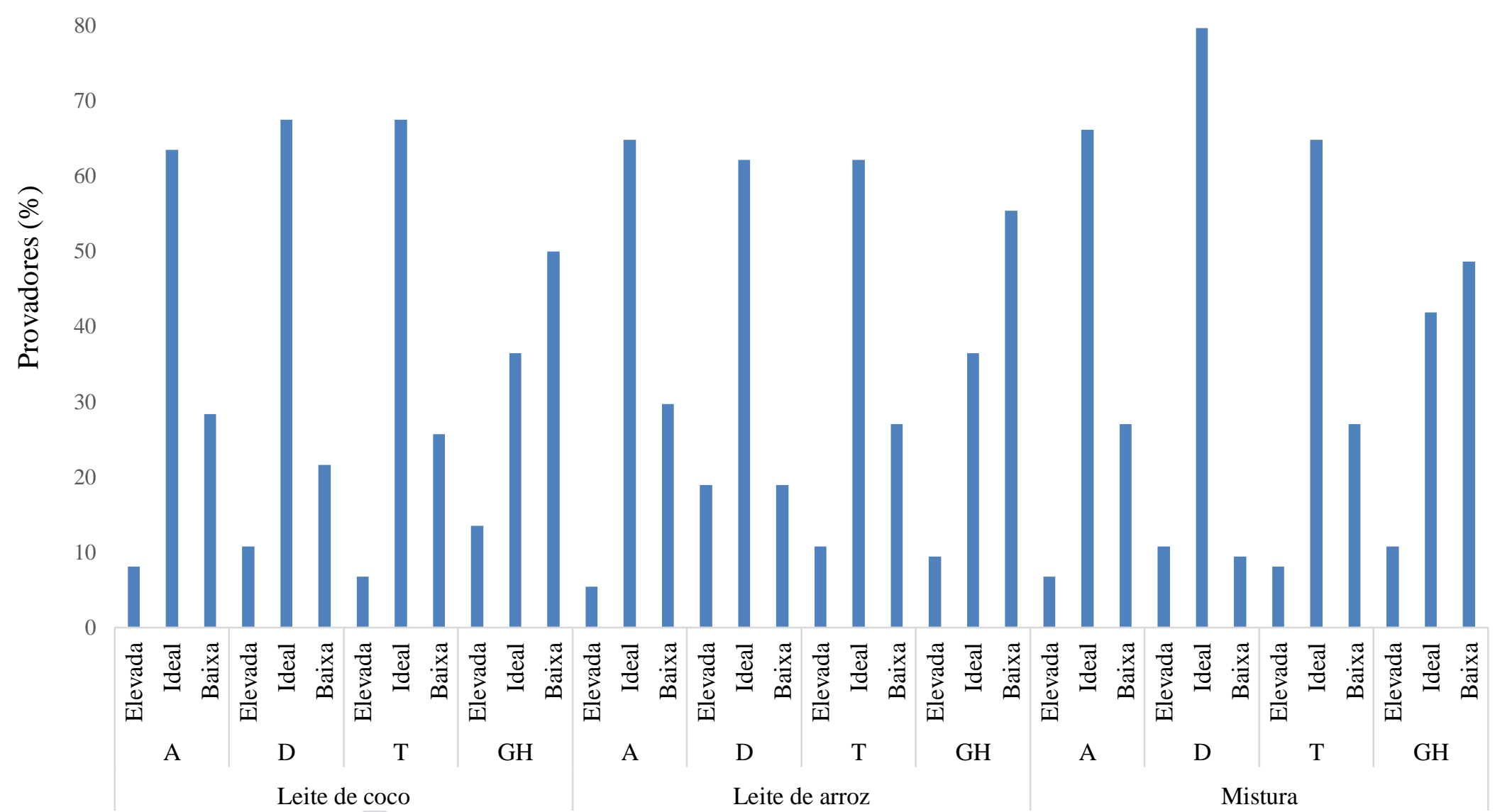

A: acidez; D: doçura; T: textura e GH: Gosto Herbáce

Fonte: Própria (2020) 


\section{UMA PARTE DO TÍTULO EM PORTUGUÊS, NEGRITO, CAIXA ALTA}

No teste de intenção de compra (Figura 2) observa-se que os sorvetes elaborados com $100 \%$ leite de coco e $100 \%$ leite de arroz receberam o mesmo percentual de intenção de compra, $27 \%$ para certamente compraria e $21 \%$ para provavelmente compraria. $\mathrm{O}$ sorvete elaborado pela mistura de ambos os leites alcançou o maior percentual de intenção de compras, uma vez que $33 \%$ dos provadores marcaram a opção de certamente comprariam. No entanto, é importante ressaltar que o percentual de indecisos é praticamente o mesmo e ainda que o percentual de intenção de compras é relativamente baixo. Desta forma, sugere-se a elaboração de sorvete vegano a base de leite de coco saborizado.

Figura 2: Representação do teste de intenção de compra para os sorvetes vegano saborizado com açai

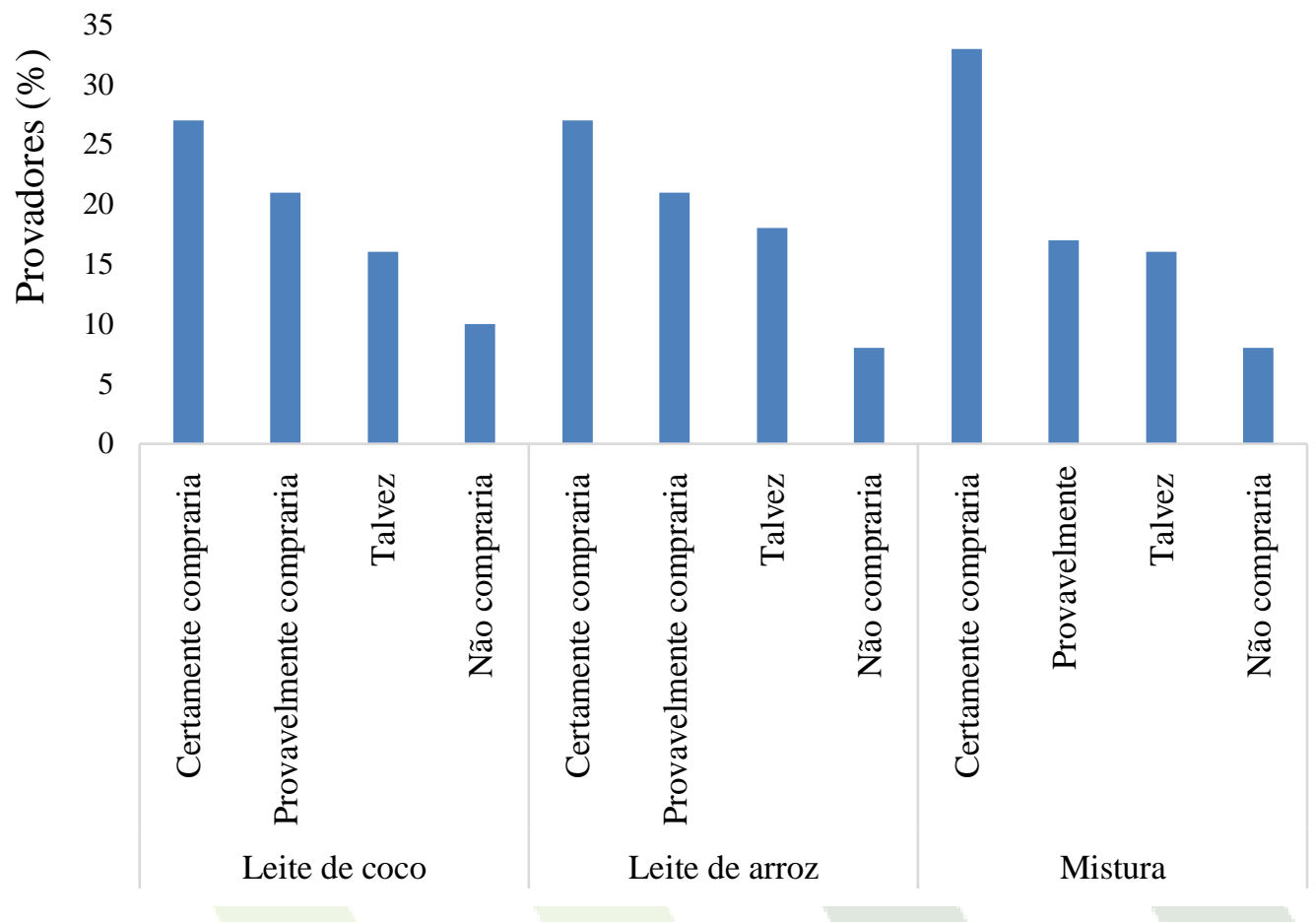

Fonte: Própria (2020)

O índice de aceitabilidade obtido pelos atributos sensoriais das formulações de sorvete vegano foram $97,38 \%$ para o sorvete elaborado com $100 \%$ com leite de coco, 96,31\% para a formulação em que o leite de coco em pó foi substituído pelo leite de arroz em pó e 97,41\% para a mistura de ambos os leites. Segundo Dutcosky (2011) para que o produto seja considerado com boa aceitação é necessário que o índice de aceitabilidade seja igual ou superior a $70 \%$. Assim, é possível afirmar que todas as formulações apresentaram um bom potencial de consumo. 


\section{CONCLUSÕES}

$\mathrm{Na}$ análise físico-química, a substituição do leite de coco em pó pelo leite de arroz e pela mistura de ambos os leites não mudou de forma pronunciada a umidade e as cinzas. Para a acidez, essa substituição resultou em uma pequena redução na acidez.

A análise sensorial mostrou que apesar dos provadores terem gostado dos sorvetes e terem classificados todos eles como ideal para os atributos avaliados, não foi possível destacar uma das formulações como preferida, sendo que todas as formulações apresentaram um bom potencial de consumo.

\section{REFERÊNCIAS}

ARAÚJO, E. R.; RÊGO, E. R. do; SAPUCAY, M. J. L. da C.; RÊGO, M. M. do; SANTOS, R. M. C. dos. Elaboração e análise sensorial de geleia de pimenta com abacaxi. Revista Brasileira de Produtos Agroindustriais, v.14, n.3, p.233-238, 2012.

BASILIO, E.C.B Legislação vigente para a produção artesanal de leite de cabra e derivados no estado de são paulo. Dissertação (Mestrado em Produção Animal). Universidade Camilo Castelo Branco, Descalvado - SP, 2016.

BRASIL. RDC n 267 , de 25 de setembro de 2003. Dispõe sobre o Regulamento Técnico de Boas Práticas de Fabricação para Estabelecimentos Industrializadores de Gelados Comestíveis e a Lista de Verificação das Boas Práticas de Fabricação para Estabelecimentos Industrializadores de Gelados Comestíveis. Brasília, DF, 2003.

BOFF, C. C.; CRIZEL, T.M.; ARAUJO, R.R.; RIOS, A.O.; FlORES, S, H, Desenvolvimento de sorvete de chocolate utilizando fibra de laranja como substituto de gordura. Ciência Rural, v.43, n.10, p.1892-1897, 2013.

CAMPIDELLI, L. L. et al. Efeitos do enriquecimento da semente de chia (Salvia hispanica) nas propriedades de sorvete de mirtilo (Vaccinium myrtillus). Revista Brasileira de Tecnologia Agroindustrial, v. 9, p. 1962-1974, 2015.

CARVALHO, F.R. Industrialização do coco - beneficiamento produção de coco ralado e leite de coco. Dossiê Técnico-Rede de Tecnologia da Bahia, 2007.

CECCHI, H. M. Fundamentos teóricos e práticos em análise de alimentos. $2^{\mathrm{a}}$. Ed. Campinas: Editora da Unicamp, 2003.

CORRADINI, S. A. S.; MADRONA, G.S.; VISENTAINER, J.V.; BONAFE, E.G.; CARVALHO, C.B.; ROCHE, P.M.; PRADO, I.N. Sensorial and fatty acid profile of ice cream manufactured with milk of crossbred cows fed palm oil and coconut fat. Journal of Dairy Science, v. 97, p. 6745-6753, 2014.

DIAS.C.S; VERSIANI, T.A.A; SILVA, D.M; SOUZA, S.A; SILVA, J.P; SILVA, M.S; MATIAS, A.D; BARBOSA, R.P; SOARES, L.J.F; MARTINS, J.A; MARTINS, N.R.T; ARCANJO, M.C.N; SOARES, P.D.F; GUSMÃO, A.C.M; FARIAS, P.K.S. Realização de teste de aceitabilidade e intenção de compra de diferentes leites vegetais de marcas 
comerciais. Revista Eletrônica Acervo Saúde. v.10, p.1522-1528, 2018.

DUTCOSKY, S.D. Análise sensorial de alimentos. 3. ed. Curitiba: Champagnat, 2011.

$\begin{array}{lllll}\text { EMBRAPA, } & \text { A } & \text { CULTURA } & \text { DO }\end{array}$ embrapa.br/digital/bitstream/item/11907/2/00078970.pdf. Acesso em 21 de abril de 2018.

GOMES, J. C.; OLIVEIRA, G. F. Análises físico-químicas de alimentos. Viçosa: UFV, 2011. IAROS, C.C; PINHEIRO, T.W. Elaboração de sorvete sem lactose enriquecido com inulina.Orientadora: Eliana Queiroz Bortolozo. 2016. 44 p. Trabalho de Conclusão de Curso (Curso Superior em Tecnologia de Alimentos). Universidade Tecnológica Federal do Paraná, Ponta Grossa,2016.

GUEDES, S.M; BEZERRA.J, R, M, V; TEIXEIRA.A, M; RIGO.M. Avaliação sensorial e físico-química de sorvete com baixo teor de lactose e adição de polpa de abacaxi (Ananas comusus L. Merril). Ambiência. v.14 n.1 p. 01 - 08, 2018.

INSTITUTO ADOLFO LUTZ - IAL. Métodos Físico-Químicos para Análise de Alimentos. São Paulo: Instituto Adolfo Lutz, 2008.

MARTINS, C.R.; JESUS JÚNIOR, L.A. Produção e Comercialização de Coco no Brasil Frente ao Comércio Internacional: Panorama 2014. Aracajú. Embrapa Tabuleiros Costeiros, 2014. 51p.

MENEZES, E.M.S.; TORRES, A.T.; SRUR, A.U.S. Valor Nutricional da polpa de açaí (Uterpe oleracea Mart) liofilizada. Acta Amazonica. v.38, n.2, p. 311-316, 2008.

PEREIRA, C. Propriedades funcionais de sorvete de morango diet com adição da enzima lactase e transglutaminase otimizada através da metodologia de superfície de resposta.Orientador: Ernani Sebastião Sant'Anna, 2014. 319p. Tese (Doutorado em Ciência de Alimentos). Universidade Federal de Santa Catarina. Florianópolis. 2014.

PEREIRA, G. G. Utilização de extrato hidrossolúvel de soja na produção de sorvete. Orientador: Jaime Vilela de Resende. 2010.166p. Dissertação (Mestrado em Ciência de Alimentos). Universidade Federal de Lavras, Lavras - MG. 2010.

PERREIRA, S, C.M; BRUMANO, L.P; KAMIYAMA, C.M; PEREIRA, J.P.F; RODARTE, M.P; PINTO, M.A.O. Lácteos com baixo teor de lactose: uma necessidade para portadores de má digestão da lactose e um nicho de mercado. Revista Instituto Laticínios "Cândido Tostes", v. 67, p. 57-65, 2012.

PEREIRA, J.A; MORAIS.O.P. As variedades de arroz vermelho brasileiras Teresina: Embrapa Meio-Norte, 2014.

PORFIRIO, M. T. Desenvolvimento, avaliação físico química e sensorial de sorvete a base de extrato hidrossolúvel de soja. Orientadora: Sumaya Ferreira Guedes. 2017. Trabalho de Conclusão. (Curso de Engenharia de Alimentos), Universidade do Estado de Mato Grosso, Barra do Bugres, 2017.

RECHSTEINER, M. S. Desenvolvimento de amidos fosfatados de batata-doce e mandioca e aplicação como substitutos de gordura em sorvetes. 2009. Tese (Doutorado em Agronomia). 
Faculdade de Ciências Agronômicas. Universidade Estadual Paulista "Júlio de Mesquita Filho". Botucatu. 2009.

RIBEIRO, F. Elaboração e caracterização físico-química de bebida mista do extrato hidrossolúvel de soja com adição de polpa de cupuaçu (Theobroma grandiflorum). Orientadora: Sumaya Ferreira Guedes. 2015. Trabalho de Conclusão de Curso (Graduação em Engenharia de Alimentos), Universidade do Estado de Mato Grosso, Barra do Bugres, 2015.

RODRIGUES, R. S.; MORETTI, R. H. Caracterização físico - química de bebida protéica elaborada com extrato de soja e polpa de pêssegos. Boletim do Centro de Pesquisa de Processamento de Alimentos, v. 26, n. 1, p. 101-110, 2008.

SCHEIN, M. Desenvolvimento de torta de sorvete vegana 2016. Monografia (Engenheiro de Alimentos), Universidade Federal do Rio Grande do Sul, Porto Alegre,2016.

SILVA JUNIOR, E. D.; LANNES, S. C. D. S. Effect of different sweetener blends and fat types on ice cream properties. Ciência e Tecnologia de Alimentos, Campinas, v. 31, n. 1, p. 217-220, 2011.

SOARES JUNIOR, M. S.; BASSINELLI, P.Z.; CALIARI, M.; VELASCO, P.; REIS, R.C.; CARVALHO, W.T. Bebidas saborizadas obtidas de extratos de quirera de arroz, de arroz integral e de soja. Ciência e Agrotecnologia, v. 34, n. 2, p. 407-413, mar. /abr. , 2010 .

SOLER, M. P.; VEIGA, P. G. Série Publicações Técnicas do Centro de Informação em Alimentos: sorvetes. Instituto de Tecnologia de Alimentos, Campinas, 2001.

SOUZA, J. C. B.; COSTA, M. R.; DE RENSIS, C. M. V.B.; SIVIERI, K. Ice cream: composition, processing and addition of probiotic. Alimentos e Nutrição, v. 21, n. 1, p. 155-165, 2010.

SOUZA, H.S.; SANTOS, A.M.; SILVA, A.M.O.; FERREIRA, I.M.; NUNES, T.P.; CARVALHO, M.G. Elaboração e avaliação da qualidade de geleia de umbu (Spondias Tuberosa Arr. C.) e mangaba (Hancornia Speciosa G.) com alegação funcional. Segurança Alimentar e Nutricional, v. 25, p.104-113, 2018.

TIMM, F. Fabricacíon de helados. Zaragoza: Acribia, 1989.340p.

ULIANA, M. R. Bebida mista de extrato de soja e suco de amora: Análises químicas e sensorial. 2009. Dissertação (Mestrado em Agronomia). Faculdade de Ciências Agronômicas. Faculdade de Ciências Agronômicas. Universidade Estadual Paulista "Júlio de Mesquita Filho". Botucatu, 2009. 
UMA PARTE DO TÍTUlo EM PORTUGUÊS, NEGRITO, CAIXA ALTA 